\title{
Influence of Late Qing Dynasty's Children Overseas Study Plan on Modern Chinese Culture
}

\author{
Dan Xu \\ Neijiang Normal University, Neijiang, 641002, China
}

Keywords: Late Qing Dynasty, Children overseas study plan, Modern culture, America

\begin{abstract}
In the middle and late nineteenth century, namely the late Qing Dynasty, the first children overseas plan of our modern times was officially implemented; this plan was applied by Rong Hong, the overseas study activity founder of our country, to the Qing government, and its purport was to dispatch domestic excellent children talents to western countries to deeply learn the advanced culture and technical knowledge of western countries and then make contributions to our country. After overcoming numerous restraints and difficulties, the overseas study plan advocated by Rong Hong was finally implemented. Afterwards, the students returned from overseas study did not disappoint our country, but played a core role in different industries. It could be said that this overseas plan had a decisive influence on the subsequent development of the society in our country, and those students had also made great contributions to the development of modern culture and science in our country.
\end{abstract}

\section{Introduction}

In the modern development history in our country, there are many historical events that have exerted an influence on cultural and scientific development, but the children overseas study plan advocated by Mr. Rong Hong was the most representative among these events, and was also an indispensable core factor facilitating the development. Its driving force to the society at that time was immeasurable, and its purport was to achieve the goal of "saving the nation" through education and to realize the purpose of vitalizing the Chinese nation; we could also say it was the plan marking the beginning of modern overseas study activities in our country, and had a significant influence on subsequent development of social culture, science and technology in China.

\section{Late Qing Dynasty's children overseas study plan going through difficulties}

The first children overseas study plan in the late Qing Dynasty was initiated by Mr. Rong Hong, a famous modern diplomat and educator; Rong Hong' secondary personal name was Chunfu, and he was born in the Nanping Village, Xiangshan County, Guangdong in the eighth year of Daoguang period in Qing Dynasty. Due to poor family situation, his parents were unable to support his study; thus, Rong Hong's father sent him to a missionary school in Macao to study when he was seven years old; later, Rong Hong decided to quit school due to his father's death of an illness and the outbreak of the Opium War. After the Opium War, Rong Hong persuaded his mother and continued the study in the missionary school; when he was eighteen years old, he followed the school principal Mr. Brown, a missionary graduated from Yale University, and went to Monson Academy in Massachusetts for further study. After the further study, Rong Hong would graduate from Yale University soon, and he made a great decision in his heart: select excellent domestic children talents and send them to western countries for study and receiving modern education just like him; when he made this decision, his overseas study career began to grow gradually ${ }^{[1]}$.

After graduation, Rong Hong came back to the motherland with the broad vision of saving the nation with knowledge. After coming back to the motherland, he began to make all efforts to find effective channels for sending domestic excellent children talents to foreign countries for further study; however, all the efforts ended in failure. Then, he and several missionaries decided to pay a secret visit to the Taiping Heavenly Kingdom, and consequently achieve the overseas study plan with the help of the force of the Taiping Heavenly Kingdom; but the fierce fighting occurred between Zeng 
Guofan and Hong Xiuquan in that period, and nobody cared about Rong Hong's plan; therefore, he could do nothing but just waited for a right moment[2]. In 1861, through recommendation by friends, Rong Hong wrote a letter of recommendation to Zhao Liewen, a bosom friend of Zeng Guofan; afterwards, with the recommendation by Zhao Liewen, Rong Hong met Zeng Guofan for the first time. For the needs of westernization movement, Zeng Guofan also was also eager to meet Rong Hong. In 1863, Zeng Guofan met Rong Hong for another two times; after careful investigation and deep understanding of Rong Hong, Zeng Guofan thought that Rong Hong was a reliable talent; then, he entrusted Rong Hong with the important mission of dispatching talents to study abroad, and gave him sixty eight thousand ounces of silver for introducing sophisticated equipment; afterwards, Rong Hong imported foreign drill machine, lathe and other high-quality and practical sophisticated industry equipment, which made the domestic industrial development reached another new level; Zeng Guofan was very pleased and appointed Rong Hong as fifth-level magistrate candidate soon; as the assistant of Ding Richang, the leader of Daotai Westernization Movement in Shanghai, they jointly established the Jiangnan manufacturing Bureau. Since then, the overseas study career of Rong Hong and Ding Richang had been started. In 1868, the second article of the Presentation of Four Items submitted by Ding Richang to the Tsungli Yamen minister Wen Xiang emphasized that the government should select excellent children talents and send them abroad for further study and for talent reserve of the country. In 1870, when going to Tianjin to assist Ding Richang in dealing with the teaching plan, Rong Hong provided more detailed regulations and policies related to children overseas study, which were submitted by Ding Richang to Zeng Guofan. At this time, Zeng Guofan finally made up his mind to implement the overseas study plan advocated by Rong Hong and to submit a written statement to the Royal court. This is the famous Memorial on Selecting Children for Study in western Europe. From that time, the overseas study plan that Rong Hong wanted to achieve was finally implemented.

\section{Reasons for selecting America}

finally agreed to select 120 smart children to participate in overseas study plan; these children were generally in their very young age and were not generally over thirteen years old; as the leader, Rong Hong dispatched them by batches to America to absorb advanced knowledge. On the steamship, these inexperienced children did not realize that the important emission of enriching and strengthen the country had fallen on their shoulders since that time; the period of violent governance by the Taiping Heavenly Kingdom had passed for almost eight years, and inside and outside wars of Qing government had stopped; the relationship between China and foreign countries was becoming stable gradually. On of the biggest domestic events in this period was the event of overseas study.

According to the official explanation, selecting America as the country where these children receive the education is related to the preferential policies under the New Sino-American Agreement. However, in my personal opinion, that is not the reason why the Qing government selected America. In the period of overseas study, not only America expressed their its attitude of welcoming Chinese students to study in its country; UK and many other western countries also welcomed the Chinese "study abroad" activities, and the knowledge and technical strength of these countries were not inferior to those of America at that time[3]. Therefore, we can see from the relation that $\mathrm{Li}$ Hongzhang, Prince Kung and Zeng Guofan selected America as the cooperative country out of their favorable impression towards America; on the other hand, Hong Rong, the planner, organizer and implementer of this plan, once studied in America, thus he would certainly select the country that he was familiar with. Besides, there were also some relevant education agreements between China and America, and these agreements stipulated that the two countries could send students to each other and mutually enjoy most preferential treatment for students. Thus, the accumulation of these factors made the Qing government select America as the cooperative country. 


\section{Profound influence of returned students on our country}

In the seventh year of the reign of Emperor Guangxu, the students studying abroad finished their long period of school life and came back to the motherland by batches, except for the 26 students who could not came back due to illness and other reasons. These students who came back to the motherland included Zhan Tianyou graduated from Yale University, etc. After they came back, Li Hongzhang made great efforts to arrange these excellent talents into different industries and posts. According to relevant data, there were 21 students arranged in domestic communication agencies to take charge of telegraph transmission, 23 students in shipyards, Jiangnan manufacturing Bureau and other units for talent reserve. There were also 50 students arranged in hospitals, machinery enterprises, military industrial enterprises and other top firms for internship. It is easy to see from such post allocation that most of these talents were arranged in institutions related to foreign affairs, which played a very important role in the early-stage cultural, scientific and technological development in our country. Especially in the aspects of culture and military technology, they obtained very outstanding achievements, which substantially promoted the social development.

Besides the military industry, scientific and technological fields, the work posts arranged by government for returned students also included translation, customs, diplomacy, doctor, lawyer, media, taxation, commerce and other relevant institutions. The $19 \%$ of the returned students started their political career, the 58\% students entered the scientific and technological industry, and the 16\% students selected culture and education, translation, commerce and other fields; but, whatever industries they selected, we could see from the subsequent development condition that these students were outstanding persons with great competitiveness in their own fields. These students became the backbone force to drive forward the development of the nation of that era[4].

Returned students' positive influence on mineral exploration and geological undertakings became a most obvious highlight after they came back from study abroad. Kuang Rongguang was the returned student who made the most obvious contributions to the geological undertakings in our country. In America, he enrolled in Lafayette College and majored in mining industry. He provided very effective help for the problem of flashing digging that was always a difficulty for Zhan Tianyou. After performing the field investigation and demonstrating the construction study, he finally surveyed the geological condition of the Zhili province, and provided the most accurate and reliable original data for geological development of this place.

The development process of modern railway undertakings in our country was almost the most backward; therefore, Zhan Tianyou put all his efforts in the railway undertakings in our country after coming back to the motherland. In the early twentieth century, under the leadership of Zhan Tianyou, etc., modern domestic talents finally constructed the first railway of our country within four years. Besides, just like the railway undertakings, the development of telegraph undertakings also got much faster due to the participation of more and more returned students. Among these returned students, there were more than 20 persons who had previously participated in the telegraph undertakings, and the Global Telegraph Rules chiefly edited by Zhou Wanpeng was the best proof showing that the telegraph technology in our country was getting advanced gradually. Besides, the first president of Tsinghua University Tang Guoan, the mining and metallurgy expert Wu Yangzeng, etc. were also very excellent representatives of the returned students at that time.

These returned students were also outstanding political talents; for example, Tang Shaoyi, the founder of Fudan University, was an excellent representative of these students; his working style of free and easy governance was very admirable; after the Xinhai Revolution was finished, Tang Shaoyi once took the post of the first prime minister of the Republic of China; however, due to arbitrary way of nation governance by Yuan Shikai, Tang Shaoyi was finally relieved of his office. After establishing the Nanjing Government, Chiang Kai-shek was intended to employ Tang Shaoyi as the senior consultant, but he refused and was willing to act as a county-level official to serve the roots level; it could be seen that this is related to the western advanced political guidance accepted by him and to his own spirit of dedication. Mao Zedong once took Tang Shaoyi as a positive case in a important political meeting to motivate leaders of different party and government departments; 
chairman Mao emphasized: Tang Shaoyi, a previous prime minister, can take the rough with the smooth and serve the people at grass-root level, why our ministers cannot get into the grass-root level? It is easy to see that chairman Mao took Tang Shaoyi as an example to not only motivate internal cadres of party and government organs, but also affirm Tang Shaoyi's spirit of being able to take the rough with the smooth ${ }^{[5]}$. Therefore, it is easy to see that these students participating in overseas study had experienced the democratic spirit of America; thus, they had more enlightened political concepts.

From the political development situation in recent years, the students studying in America played a gradually enhanced role in nation development after they came back from study abroad. Although attention was not paid to them when they initially came back, the government finally paid more attention to these talents when they gradually showed their own abilities in different fields and on different posts, and selected outstanding personnel from these talents to act as government officials and serve the country; these talents became the vanguard to overthrow the feudal regime. After the establishment of the Republic of China, these returned students joined in the revolution and become the backbone force of promoting the modern history process of our country.

Moreover, returned students also played a very important role in the friendly relationship between China and America, and effectively promoted the development of relationship between China and America. In 1972, President Nixon visited China, and Mao Zedong and Zhou Enlai quickly selected and dispatched four children to America for studying the translation; this was also the first time to dispatch students for study abroad during the Great Cultural Revolution, and there were over one hundred years passed since the children overseas plan of Rong Hong. On June 23, 1978, when hearing the work report by the Ministry of Education: Deng Xiaoping pointed out; "I agree to increase the number of students to be dispatched for study abroad. Thousands of students need to be dispatched, rather than just several students". Since then, China had dispatched a large scale of students for study abroad, and the Chinese history of study abroad entered a brand new era. On December 26 of the same year, the first batch of visiting scholars after the reform and opening-up were dispatched for further study abroad, and the country selected was also America. In 2006, Mr. Hu Jintao visited America, told Rong Hong's overseas study plan and experience to students in Yale University, and invited students and teachers of this university to visit China. Yale University gave two gifts to Hu Jintao: one of them is Rong Hong's half-length photo taken when Rong Hong studied in Yale University, and the other one is an Chinese ancient book Kangxi Dictionary that was given by Rong Hong to Yale University. It could be seen that Rong Hong was still the bond to maintain the relationship between China and America after more than one hundred years.

\section{Conclusion}

In the context above, we reviewed the children overseas study activity that once obtained a glorious achievement in our history; although its implementation process was full of difficulties due to various reasons, these students studying abroad did not disappoint our country; they acted as very good pathfinders of our country lacking various resources, threw themselves into different fields, made their contributions to the improvement of the national power, were brave in innovation in culture, scientific research, politics, education and many other fields, broke traditional pioneers, and were heroes for development and pioneering of our country. Therefore, we can say that the late Qing Dynasty's children overseas study plan marking the beginning of modern overseas study movement in our country was a turning point of driving our country towards prosperous development, and played a very important role in promoting the prosperity and strength of our nation.

\section{References}

[1] Shao Liming. The Influence of Late Qing Dynasty's Overseas Education on Chinese Culture. Age of Literature, 2014 (8): 217-218. 
[2] Chen Zhilan. The Influence of Rong Hong's Late Qing Dynasty Children Overseas Study Plan on Modern China. Journal of Huaibei Normal University (philosophy and social science edition), 2014 (2): 81-83.

[3] Bi Yanting. An Analysis on the First Overseas Study Dispatched by the Government in Late Qing Dynasty. Heilongjiang Historical Annals, 2014 (14): 26-27.

[4] Guo Xudong. Analysis on the Formation, Characteristics and Influence of Late Qing Dynasty's Children Study in America. Journal of Liaocheng University (social science edition), 2010 (2): 254-255.

[5] Wang Xiaoying. The Position and Function of Lingnan Overseas Students in the Chinese Modern Overseas Study History. Overseas Chinese History Studies, 2003 (4): 54-61. 